\title{
An outbreak of feline infectious peritonitis in a Taiwanese shelter: epidemiologic and molecular evidence for horizontal transmission of a novel type II feline coronavirus
}

\author{
Ying-Ting Wang ${ }^{1}$, Bi-Ling Su${ }^{2}$, Li-En Hsieh ${ }^{1}$ and Ling-Ling Chueh ${ }^{1 *}$
}

\begin{abstract}
Feline infectious peritonitis (FIP) is a fatal disease caused by feline coronavirus (FCoV) infection. FCoV can be divided into serotypes I and II. The virus that causes FIP (FIPV) is believed to occur sporadically and spread infrequently from cat to cat. Recently, an FIP outbreak from an animal shelter was confirmed in Taiwan. FCoV from all the cats in this shelter were analyzed to determine the epidemiology of this outbreak. Thirteen of 46 (28.2\%) cats with typical signs of FIP were identified. Among them, seven cats were confirmed by necropsy and/or histopathological examinations. Despite the fact that more than one FCoV was identified in this multi-cat environment, the eight FIP cats were invariably found to be infected with a type II FCoV. Sequence analysis revealed that the type II FIPV detected from fecal samples, body effusions and granulomatous tissue homogenates from the cats that succumbed to FIP all harbored an identical recombination site in their $S$ gene. Two of the cats that succumbed to FIP were found to harbor an identical nonsense mutation in the $3 \mathrm{c}$ gene. Fecal shedding of this type II virus in the effusive form of FIP can be detected up to six days before death. Taken together, our data demonstrate that horizontal transmission of FIPV is possible and that FIP cats can pose a potential risk to other cats living in the same environment.
\end{abstract}

\section{Introduction}

Feline infectious peritonitis (FIP) is a fatal disease in cats caused by feline coronavirus (FCoV). FCoV is an enveloped, positive-stranded RNA virus belonging to genus Alphacoronavirus, family Coronaviridae, within the order Nidovirales. The genome size of FCoV is approximately $28.9 \mathrm{~kb}$, including a non-structural replicase gene; four structural genes encoding the spike (S), envelope, membrane and nucleocapsid proteins; and five accessory genes $3 a b c$ and $7 a b$ [1].

Feline coronaviruses cause mild to inapparent and transient infections of the gut and are ubiquitous in cat populations worldwide [2]. They exist in two serotypes, I and II [3]. Type I FCoV is predominant in the field, whereas type II virus represents only $2-30 \%$ of infection

\footnotetext{
* Correspondence: linglingchueh@ntu.edu.tw

${ }^{1}$ Graduate Institute of Veterinary Medicine, School of Veterinary Medicine, National Taiwan University, Taipei 10617, Taiwan

Full list of author information is available at the end of the article
}

[4-8]. Accumulating genetic evidence indicates that type II FCoV have arisen by two homologous recombinations between type I FCoV and canine $\mathrm{CoV}$ (CCoV) $[9,10]$. Both serotypes can mutate in the host to acquire macrophage tropism and cause a systemic disease known as feline infectious peritonitis $[2,11,12]$. Due to a lack of virus-shedding in studies of FIP cats, the mutant FIP viruses (FIP causing FCoV, FIPV) are presumably contained only within the diseased tissues and not transmitted by cat-to-cat contact under natural circumstances $[2,11,13,14]$.

In this paper, we report herein on an epizootic of FIP in a Taiwanese shelter that was caused by a novel type II FCoV. Epidemiological and molecular studies of isolates from various healthy and affected cats in this shelter strongly suggest that this virus was brought in by the introduction of kittens from another shelter with subsequent horizontal spread to co-housed adult cats.

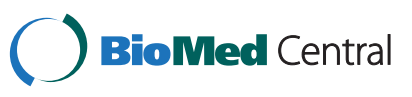

(c) 2013 Wang et al.; licensee BioMed Central Ltd. This is an Open Access article distributed under the terms of the Creative Commons Attribution License (http://creativecommons.org/licenses/by/2.0), which permits unrestricted use, distribution, and reproduction in any medium, provided the original work is properly cited. 


\section{Materials and methods}

\section{Animals and specimen collection}

A total of 46 cats from a private cat shelter were subjected to this study from September 2011 to August 2012. The shelter houses adult cats and occasionally some kittens. All of the cats were either stray animals or had been rescued, and some of them were being temporally raised at the homes of various private cat rescuers. Before this outbreak, all cats were living together in a cageless indoor environment and shared food, water bowls and litter boxes. Some of the cats were siblings, and the others were unrelated (Table 1).

Feces or rectal swab samples of all asymptomatic cats were collected at least once to monitor the presence of FCoV. For cats showing signs of illness suspected to be FIP, body effusions, whole blood and swab samples, including rectal, nasal, oral and conjuctival swabs, were collected routinely. In addition to supportive care, these FIP-suspected animals were subjected to treatment with prednisolone (Prelon ${ }^{\circledR}$, YF Chemical Corp., New Taipei City, Taiwan), benazepril (Cibacen ${ }^{\oplus}$, Novartis, Barbera del Valles, Spain) and recombinant human interferon alpha (Roferon ${ }^{\circ}$-A, Roche, Basel, Switzerland). Cats that succumbed to illness were subjected to necropsy for pathological confirmation. Upon necropsy, body effusions were first drawn by needle and syringe, followed by collecting swabs, whole blood, urine and granulomatous lesions in the internal organs. All samples were frozen at $20{ }^{\circ} \mathrm{C}$ until use. All specimens were screened for FCoV by reverse transcription-nested polymerase chain reaction (RT-nPCR) [15]. The specimens that tested positively were subsequently subjected to further analysis.

\section{Sample preparation and reverse transcription}

Swab samples were suspended in $1 \mathrm{~mL}$ of $0.1 \%$ diethyl pyrocarbonate (DEPC)-treated water. Fecal samples were suspended with 9 times of $0.1 \%$ DEPC-treated water by vortexing. The suspension was centrifuged, and the supernatant was transferred into a new tube. Approximately $0.5 \mathrm{~g}$ tissues were frozen and then ground with a mortar and pestle in the presence of $2 \mathrm{~mL}$ of Trizol [16]. Total RNA was extracted from $300 \mu \mathrm{L}$ of swab suspension, whole blood, fecal suspension, tissue homogenate and body effusion using Trizol. Twenty-one microliters of isolated RNA were reverse transcribed with templatespecific primer N1 (5'-gctacaattgtatcctcaac- $\left.3^{\prime}\right)$ or P211 [15] with Moloney murine leukemia virus reverse transcriptase (Invitrogen, CA, USA). The reaction was incubated at $37^{\circ} \mathrm{C}$ for $60 \mathrm{~min}, 72^{\circ} \mathrm{C}$ for $15 \mathrm{~min}$ and finally, at $94^{\circ} \mathrm{C}$ for $5 \mathrm{~min}$.

\section{Typing of FCoV using nested PCR}

For typing of FCoV, nested PCR was performed according to the procedures reported by Addie et al. [5] with slight modification. Following reverse transcription, $5 \mu \mathrm{L}$ of the complementary DNA was added to $25 \mu \mathrm{L}$ of the PCR mixture (Invitrogen, CA, USA) according to the manufacturer's instructions for the following primer sets: S1 and Iffs for type I FCoV detection and S1 and Icfs for type II FCoV detection. Nested PCR was performed on $2 \mu \mathrm{L}$ of the first PCR product using nested primers. The expected size of the second PCR yielded for type I and II FCoV were 360 and $218 \mathrm{bp}$, respectively. The products of RTnPCR were electrophoresed, and then, target DNA fragments were purified (Geneaid Biotech, Ltd, Taipei) and sequenced (Mission Biotech, Taipei, Taiwan) from both orientations.

Amplification, sequencing and analysis of $3 a$ and $3 c$ gene from the type II FCoV

To amplify the $3 a$ gene of type II FCoV from FIP cats, a specific primer set that can amplify from the type II $S$ gene to the $3 a$ gene was designed. Complementary DNA amplified with the primer set targeted the 3 ' end of the type II FCoV $S$ gene (Icfs) and $5^{\prime}$ end of the FCoV $3 a$ gene (3aR2: $5^{\prime}$-caccaaaacctatacacacaag- $3^{\prime}$ ). The temperature cycling consisted of 5 min of preheating at $94^{\circ} \mathrm{C}$; $35 \mathrm{cy}-$ cles of denaturation at $94^{\circ} \mathrm{C}$ for $20 \mathrm{~s}$, annealing at $50^{\circ} \mathrm{C}$ for $20 \mathrm{~s}$ and extension at $72^{\circ} \mathrm{C}$ for $30 \mathrm{~s}$; and a final extension at $72^{\circ} \mathrm{C}$ for $5 \mathrm{~min}$. Following a second round of amplification with the primers nIcfs and $3 \mathrm{aR} 2$, the expected size of the product was approximately $600 \mathrm{bp}$. The amplicons were electrophoresed, purified and sequenced from both orientations to confirm the nucleotide sequences.

To amplify the $3 c$ gene of type II FCoV from FIP cats, specific primer sets that can amplify from the 3 ' end of the type II $S$ gene to the $3 c$ gene were designed. Complementary DNA were amplified with the forward primer (Icfs) and reverse primer (E68R: 5' -aatatcaatataattatctgctgga-3' and/or N21R: $5^{\prime}$-gttcatctcccagttgacg-3'). The temperature cycling consisted of $5 \mathrm{~min}$ of preheating at $94^{\circ} \mathrm{C} ; 40$ cycles of denaturation at $94^{\circ} \mathrm{C}$ for $30 \mathrm{~s}$, annealing at $46^{\circ} \mathrm{C}$ for $30 \mathrm{~s}$ and extension at $72^{\circ} \mathrm{C}$ for $90 \mathrm{~s}$; and a final extension at $72^{\circ} \mathrm{C}$ for $7 \mathrm{~min}$. Following a second round of amplification with primer nIcfs and E68R, the products were electrophoresed, purified and sequenced from both orientations to confirm the nucleotide sequences.

\section{Phylogenetic analysis and recombination site analysis of a type II FCoV}

Multiple sequence alignments were preformed with ClustalW 2.0 and manually edited in EditSeq (DNASTAR, Madison, USA). Phylogenetic analyses were conducted using MegAlign, version 7.2.1 (DNASTAR, Madison, USA). Bootscan and similarity graphs were prepared with SimPlot 3.5.1 software (SCRoftware, Baltimore, USA). 
Table 1 Information for all FIP-suspected and confirmed cats from the cat shelter

\begin{tabular}{|c|c|c|c|c|c|c|c|}
\hline Cat no & $\mathrm{Age}^{1}$ & $\begin{array}{l}\text { Date of enter } \\
\text { the shelter }\end{array}$ & $\begin{array}{l}\text { Date of } \\
\text { fever onset }\end{array}$ & Date of death & Clinical findings & Necropsy findings & Effusive/non-effusive \\
\hline 1 & $3 m$ & Jun. 16, 2011 & Aug. 17, 2011 & Sep. 01, 2011 & Fever, anorexia, ascites, neurological signs & & \\
\hline $2^{a}$ & $4 m$ & Aug. 06, 2011 & $N A^{2}$ & Sep. 21, 2011 & Clinical signs unavailable & & \\
\hline $3^{b}$ & $3 m$ & Jul. 11, 2011 & Aug. 18, 2011 & Sep. 25, 2011 & Fever, anorexia, weight loss, neurological signs & & \\
\hline 4 & $2.5 \mathrm{~m}$ & Jun. 08, 2011 & Aug. 16, 2011 & Sep. 28, 2011 & Fever, ascites, neurological signs & & \\
\hline $5^{a}$ & $4 m$ & Aug. 06, 2011 & Aug. 15, 2011 & Oct. 20, 2011 & Fever, pleural effusion, diarrhea & & \\
\hline 6 & $7 \mathrm{~m}$ & Apr. 24, 2011 & NA & Oct. 22, 2011 & Anorexia, weight loss, neurological signs & & \\
\hline 7 & $3 y 6 m$ & Resident & NA & Oct. 27, 2011 & & $\begin{array}{l}\text { Ascites, jaundice, granulomatous lesion in kidney, } \\
\text { fibrinous peritonitis }\end{array}$ & Effusive \\
\hline 8 & $6 \mathrm{~m}$ & Jul. 11, 2011 & NA & Dec. 14, 2011 & & $\begin{array}{l}\text { Granulomatous changes in kidney, liver, lung, brain } \\
\text { and eyes }\end{array}$ & Non-effusive \\
\hline 9 & $2 y$ & Resident & NA & Dec. 28, 2011 & & $\begin{array}{l}\text { Ascites, pleural effusion and pericardial effusion, } \\
\text { granulomatous changes in kidney, liver and intestine }\end{array}$ & Effusive/non-effusive \\
\hline $10^{\mathrm{b}}$ & $3 m$ & Jul. 11, 2011 & NA & Nov. 05, 2011 & & Granulomatous changes in kidney, liver and omentum & Non-effusive \\
\hline $11^{c}$ & $1 \mathrm{y} 6 \mathrm{~m}$ & Resident & NA & Feb. 14, 2012 & & $\begin{array}{l}\text { Ascites and pleural effusion, jaundice, fibrinous peritonitis, } \\
\text { granulomatous changes in kidney, liver, lung and spleen. }\end{array}$ & Effusive/non-effusive \\
\hline $12^{c}$ & $1 \mathrm{y} 6 \mathrm{~m}$ & Resident & NA & Mar. 19, 2012 & & $\begin{array}{l}\text { Jaundice, fibrinous peritonitis, granulomatous changes in } \\
\text { thoracic and abdominal wall, kidney, liver, lung, spleen } \\
\text { omentum, and eyes. }\end{array}$ & Effusive/non-effusive \\
\hline 13 & $1 \mathrm{y} 7 \mathrm{~m}$ & Resident & NA & Apr. 13, 2012 & & $\begin{array}{l}\text { Jaundice, enlargement of liver and mesenteric lymph } \\
\text { node, granulomatous changes in kidney and lung. }\end{array}$ & Non-effusive \\
\hline
\end{tabular}

${ }_{1}$ Age of the cats when clinical signs of FIP appeared.

2 Not available.

a, b, c: Siblings. 


\section{Results}

Confirmation of an FIP outbreak in the cat shelter

The shelter had been ongoing for three-and-a-half years. No history of FIP was recorded before August 2011. Kittens (cat 1, 3, 4, 8 and 10) were introduced to this shelter between June and July 2011. After entering, these kittens played together and lived with the resident adult cats. Before the outbreak, the kittens were taken individually to a veterinarian for vaccinations and attended adoption activities. Fever was first observed in four of the kittens (cat 1, 3, 4,5) within a period of a few days (from August $15_{\text {th }}$ to $18_{\text {th }}$ ) (Table 1). Clinical signs, e.g., fever, anorexia, neurological signs, panting and/or abdominal extension were observed for the following two months and the kittens died sequentially between September $1_{\text {st }}$ and October $22_{\text {nd }}$ (Table 1 ). The caregivers at the shelter requested our help on September 27 th. All of the resident cats in the shelter were immediately screened for FCoV using RT-nPCR. All FCoV positive cats were isolated individually and kept separated. Nevertheless, starting in September, some of the adult cats with FIP (cats 7-13) showed clinical signs similar to those of the kittens and all of them died later.

Six kittens (cats 1-6) with body effusions and/or neurological signs succumbed within the first two months without necropsy confirmation (Table 1). Cat 1 was once presented to our teaching hospital, and ascites was taken from the cat. In cats 7-13, typical necropsy features, characterized by ascites and/or pleural effusions in the body cavities (effusive FIP) and granulomatous lesions in several organs, especially the kidney, liver, lung, omentum and eyes (non-effusive FIP), were found. Cats 9, 11 and 12 manifested mixed forms of the disease at necropsy (Table 1 ).

Altogether, 13 of 46 cats (28.3\%) died from FIP between September 2011 and April 2012. During this period, 33 cats $(71.7 \%)$ appeared to be clinically healthy, and 26 of these asymptomatic cats $(78.7 \%)$ were positive at least once for FCoV detection in their feces by RTnPCR. The other seven of these asymptomatic cats were negative for FCoV detection (Table 2).

Type II FIPV were consistently detected in the FIPsuccumbed cats

To further investigate the relationship between these seven histopathologically confirmed FIP cats, amplified DNA were typed, sequenced and analyzed. Type II FIPV were detected in all eight of the animals that succumbed to FIP in their swab samples, feces, urine, body effusions, cerebrospinal fluids and tissue homogenates (Table 3). Type II viruses that cause FIP were found not only in the diseased tissue but also in the fecal samples (cat 7, 11, 12 and 13), nasal/oral/conjunctival swab samples (cat $7,8,9,11$ and 12), and urine collected by cystocentesis
Table 2 Detection and typing of FCoV in fecal samples from healthy cats in the same shelter

\begin{tabular}{|c|c|c|c|c|c|}
\hline \multirow[t]{2}{*}{ No. } & \multicolumn{4}{|c|}{ FCoV } & \multirow[t]{2}{*}{ Type } \\
\hline & Oct. 2011 & Feb. 2012 & Jun. 2012 & Jul. 2012 & \\
\hline 14 & ++ & ++ & ++ & + & untypable \\
\hline 15 & - & + & - & & untypable \\
\hline 16 & ++ & - & - & & untypable \\
\hline 17 & ++ & ++ & + & ++ & । \\
\hline 18 & ++ & ++ & ++ & ++ & । \\
\hline 19 & - & & - & + & untypable \\
\hline 20 & - & & - & + & untypable \\
\hline 21 & - & & - & - & \\
\hline 22 & ++ & ++ & - & & untypable \\
\hline 23 & + & ++ & - & + & I \\
\hline 24 & - & + & - & & untypable \\
\hline 25 & ++ & ++ & + & + & I \\
\hline 26 & - & & + & - & untypable \\
\hline 27 & ++ & ++ & + & + & । \\
\hline 28 & ++ & ++ & ++ & + & । \\
\hline 29 & - & & - & - & \\
\hline 30 & - & ++ & ++ & - & I \\
\hline 31 & - & & & - & \\
\hline 32 & + & ++ & - & - & I \\
\hline 33 & - & & ++ & - & untypable \\
\hline 34 & ++ & & & & । \\
\hline 35 & - & & + & + & untypable \\
\hline 36 & ++ & ++ & + & - & I \\
\hline 37 & & & - & & \\
\hline 38 & & & + & & untypable \\
\hline 39 & & ++ & + & + & I \\
\hline 40 & & - & + & - & untypable \\
\hline 41 & & + & - & + & untypable \\
\hline 42 & & & + & - & untypable \\
\hline 43 & & & - & & \\
\hline 44 & & & & - & \\
\hline 45 & & & & - & \\
\hline 46 & & & + & & untypable \\
\hline
\end{tabular}

(cat 11) (Table 3). Although there was no necropsy, the ascites from cat 1 , the first FIP death in this cat shelter, was available for analysis. This cat was confirmed to be infected with a type II virus. From the healthy animals, only type I or untypable FCoV were detected from the fecal samples (Table 2). Cats 8, 9 and 13 were coinfected with both types of FCoV (Table 3). Although more than one $\mathrm{FCoV}$, i.e., type I, II or untypable viruses, was found to circulate in this multi-cat environment, the 
Table 3 The characteristics of $3 c$ genes of FCoV recovered from various specimens of FIP cats

\begin{tabular}{|c|c|c|c|c|c|c|c|c|c|c|c|c|c|c|c|c|c|c|c|}
\hline \multirow{2}{*}{$\begin{array}{l}\text { Case } \\
\text { no. }\end{array}$} & \multicolumn{11}{|c|}{ Genotype of FCoV } & \multirow{2}{*}{$\begin{array}{l}\text { S gene } \\
\text { crossover } \\
\text { site }\end{array}$} & \multicolumn{7}{|c|}{ Integrity of the $3 c$ gene ${ }^{b}$} \\
\hline & NOC & $R / F$ & $U$ & $A / P$ & CSF & $\mathrm{Li}$ & Lu & Ki & $B r$ & $S p$ & $\operatorname{lnt}$ & & $R / F$ & $A / P$ & $L i$ & Lu & Ki & $B r$ & $S p$ \\
\hline 1 & & & & $\|$ & & & & & & & & $4250^{a}$ & & intact & & & & & \\
\hline 7 & $\|$ & $\|$ & & $\|$ & & $\|$ & $\|$ & $\|$ & $\|$ & $\|$ & & 4250 & intact & & intact & intact & intact & & intact \\
\hline 8 & $\|$ & । & & & & + & $\|$ & $\|$ & + & - & - & & & & & & & & \\
\hline 9 & $\|$ & । & & $\|$ & & + & $\|$ & & $\|$ & $\|$ & + & 4250 & & $\mathrm{G} 210^{*}$ & & & & $\mathrm{G} 210^{*}$ & G210* \\
\hline 10 & & & & & & + & + & $\|$ & $\|$ & & $\|$ & 4250 & & & & & intact & & \\
\hline 11 & $\|$ & $\|$ & $\|$ & $\|$ & + & $\|$ & $\|$ & $\|$ & & + & & 4250 & & & & $\mathrm{E} 47^{*}$ & & & \\
\hline 12 & $\|$ & $\|$ & & $\|$ & $\|$ & + & $\|$ & $\|$ & & $\|$ & + & 4250 & $\mathrm{G} 210^{*}$ & $\mathrm{G} 210^{*}$ & & & & & \\
\hline 13 & & $|/| \mid$ & & & + & + & + & $\|$ & $\|$ & + & & 4250 & & & & & & Q218* & \\
\hline
\end{tabular}

$N O C$, nasal/oral/conjunctival swabs; $R / F$, rectal swabs or fecal samples; $A / P$, ascites or pleural effusions; $C S F$, cerebrospinal fluid; $L i$, liver; $L u$, lung; $K i$, kidney; $B r$, brain; Sp, spleen; Int, intestine.

$+:$ FCoV positive but the type of virus cannot be determined.

-: FCoV negative.

a: FCoV/NTU2/R/2003; GenBank: DQ160294.

b: E47*, G210* and Q218*: truncated 3c proteins with premature stop codons at amino acids 47, 210 and 218 were found, respectively.

eight FIP cats were consistently found to be infected with a type II FCoV, whereas the healthy cats were not (Tables 2 and 3).

\section{A type II FIPV of the same origin was detected from FIP- succumbed cats}

To further investigate the relationship of these diseaseassociated type II viruses isolated from FIP-succumbed cats, specific primer sets that can specifically amplify from the 3' end of type II $S$ gene to a downstream gene were used to analyze the viral sequences. The identity of the 620 bp amplicons derived from seven type II FIPV was approximately $98.7 \%$ to $99.8 \%$. Phylogenetic analysis revealed that the type II FCoV derived from this outbreak were all grouped in a separate cluster, distinct from the other four type II FCoV currently available in the GenBank, i.e., FIPV 79-1146 (GenBank: DQ010921), FCoV 79-1683 (GenBank: JN634064), FCoV DF-2 (GenBank: DQ286389) and FCoV NTU156 (GenBank: GQ152141) (data not shown).

A recombination event at the $3^{\prime}$ end of the $S$ gene with the putative recombination site located at nucleotide 4250 was identified from all of the type II FCoV derived from the body effusions and tissue homogenate of cats 1, 7, 9, 10, 11, 12 and 13 (Additional file 1) (Table 3). Sequences upstream from this site show a higher similarity to $\mathrm{CCoV}$, whereas sequences downstream from this site were more similar to type I FCoV (Figure 1). These findings highly suggest that the type II FCoV recovered from all of the FIP cats were from a common origin.

\section{An identical nonsense mutation in $3 c$ gene was found in} two FIP-succumbed cats

To further analyze the relationship of these FIPV, $3 c$ genes, the proposed virulence-associated factor of FIP, were amplified from disease-related type II FCoV. Mutated $3 c$ genes with an identical premature stop codon at nucleotides 628-630 (amino acid 210, G210*) were found in two FIP cats, including cats 9 (ascites, spleen and brain) and 12 (ascites and rectal swabs from the day it succumbed and four days before) (Figure 2A). It is noteworthy that the FIPV shed from cat 12 harbored an identical nonsense mutation as the virus in its ascites. Intact $3 c$ genes were detected from cats 1,7 and 10 , which had previously succumbed to FIP. Two more distinct nonsense mutations were identified from cats 11 $\left(\mathrm{E} 47^{*}\right)$ and $13\left(\mathrm{Q} 218^{*}\right)$ (Figure 2A-B, Table 3).

\section{Shedding of the type II FIPV can be detected at the terminal stage of FIP cats}

The presence of FCoV was continuously analyzed to elucidate the possible route of shedding and transmission of FIPV. Disease-associated type II FCoV were found to shed through nasal/oral/conjunctival and fecal routes (Table 4). Fecal and nasal/oral/conjunctival shedding of this type II virus can be detected from the $6_{\text {th }}$ day (cat 11) and $4_{\text {th }}$ day (cat 12) respectively, before death. Viremia could be detected during the terminal stage in the cats with FIP, up to 18 days before death, and simultaneous fecal shedding was noted in one cat (cat 12) (Table 4).

\section{Discussion}

The possibility of horizontal transmission in FIP is generally questioned because (i) the occurrence of FIP is sporadic, and a single cat developing FIP in a multi-cat environment is common [2]; (ii) the internal mutation theory, which describes that FIPV is a mutant generated from enteric FCoV in one cat $[12,17]$; (iii) there is a lack of evidence of mutant FIPV shedding from FIP cats; and 


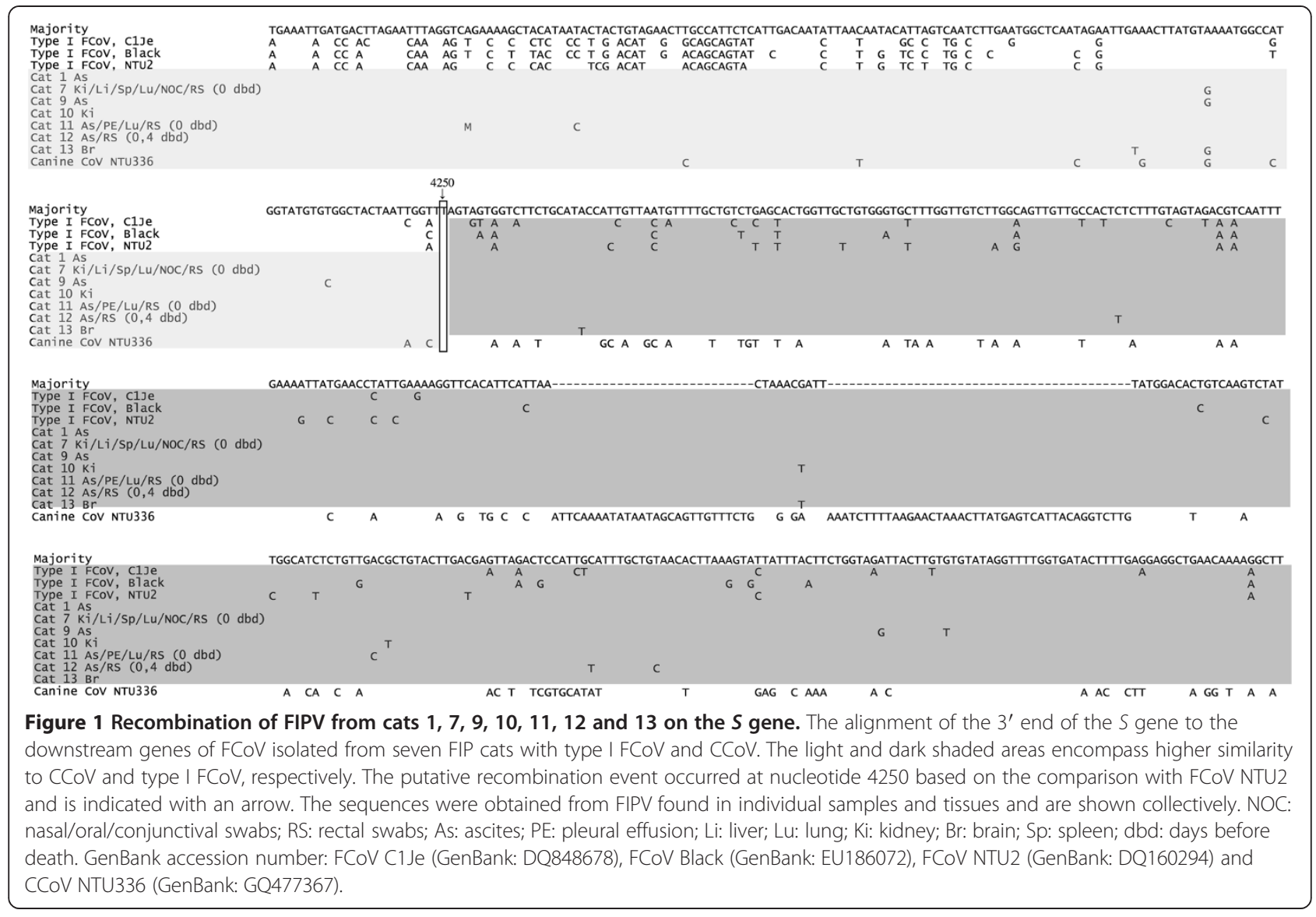

(iv) the mutation of the $3 c$ gene is unique to each FIP cat $[11,13,18]$. The current belief is that cats that succumb to FIP do not shed and transmit the FIPV to other cats $[11,13,14,18-20]$. Our data indicate that this outbreak of FIP was caused by viruses from the same origin. First, all of the FIP losses involved a type II FIPV infection, and the recombination event of these seven type II viruses was mapped to the same site. The recombination sites of the type II viruses currently available in GenBank, i.e., FIPV 79-1146, FCoV 79-1683 and FCoV NTU156, were all unique and occurred independently $[9,10]$. Second, the FIPV identified in the three kittens that died within the first two months after the onset of fever harbored an intact $3 c$ gene, whereas the viruses from the cats that survived longer (died four to eight months later) all bore a nonsense mutation, i.e., G210* (cat 9 and 12), E47* (cats 11) and Q218* (cat 13). Because the three nonsense mutations detected in the FIPV from these animals were all located at different sites, the viruses that originally infected these cats should all harbor an intact $3 c$ gene - like the virus recovered from the kittens that succumbed earlier. After infection, point mutations arose during the replication of the virus in the individual cats, giving rise to FIPV with a $3 c$ gene bearing nonsense mutations at different locations. The finding that the viruses that were identified not only in the tissues but also in the fecal samples of two cats (cat 9 and 12) harbored an identical mutation in the $3 c$ gene further confirmed that horizontal transmission had occurred (Table 3). Taken together, all these findings demonstrated that a highly virulent FIPV had spread from animal to animal in a horizontal manner.

This is the first report of a type II FIPV outbreak with evidence of horizontal transmission of a diseaseassociated FCoV. The outbreak of FIP started after introducing five kittens (cat 1, 3, 4, 8 and 10) into this shelter between June and July of 2011. Because the causative type II viruses with the distinct genetic marker in the $\mathrm{S}$ gene were confirmed to be a recombinant of feline and canine coronaviruses and some of the kittens that died earlier were found to have been living closely with dogs between being rescued and entering the shelter, any of these kittens could have been the source of this type II virus. Dogs, and especially young dogs, in shelters often shed large amounts of canine coronavirus in their feces and recombination between cat and dog and dog and pig coronaviruses has been well documented [21-23]. Additionally, these causative type II viruses 


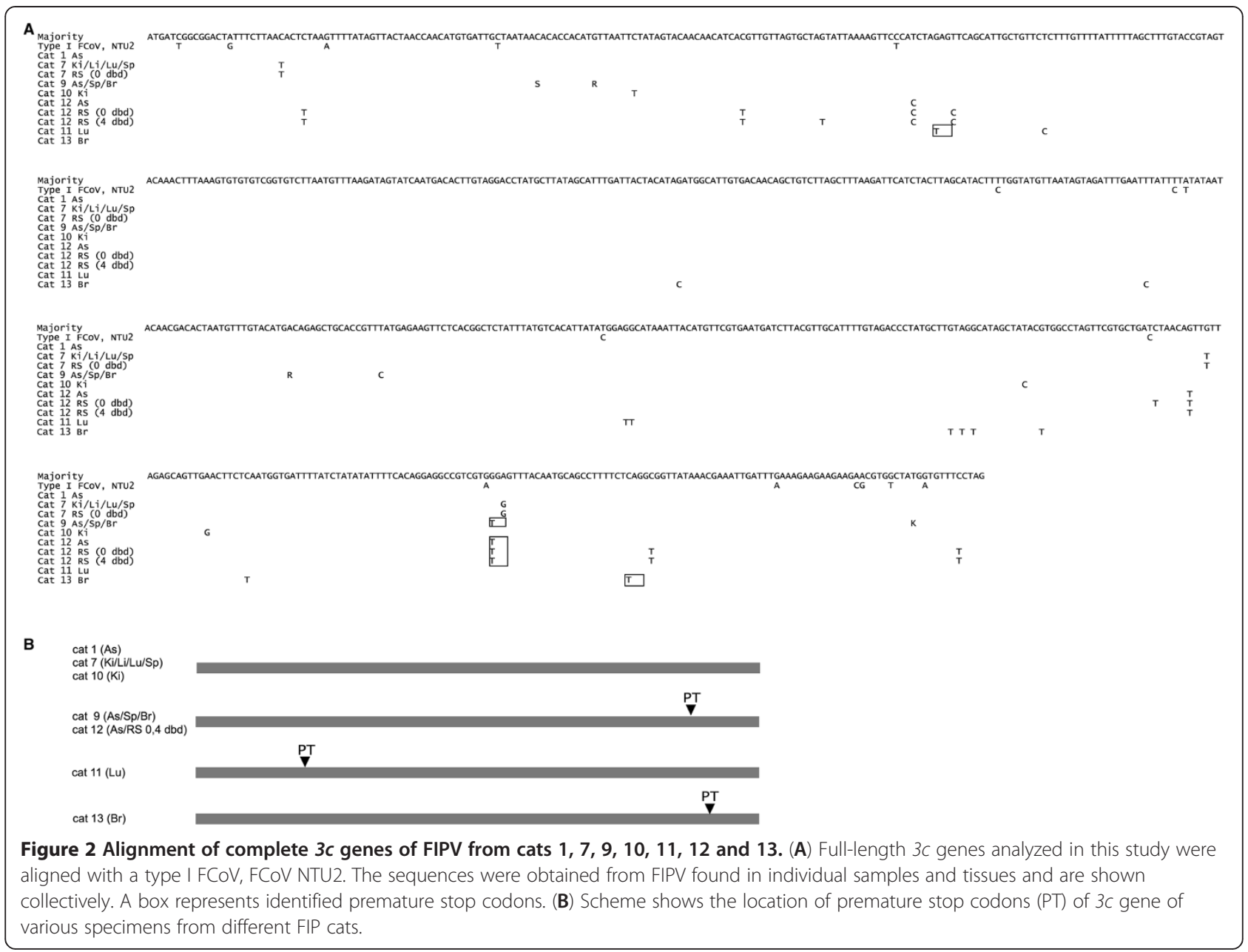

Table 4 Shedding and serotypes of feline coronavirus detected in FIP cats in the cat shelter

\begin{tabular}{|c|c|c|c|c|c|c|c|c|c|c|c|c|c|c|c|c|c|c|c|}
\hline \multirow{2}{*}{$\begin{array}{l}\text { Cat } \\
\text { no. }\end{array}$} & \multirow[t]{2}{*}{ Sample } & \multicolumn{18}{|c|}{ Days before death } \\
\hline & & -80 & -66 & -60 & -57 & -50 & -43 & -36 & -29 & -25 & -23 & -20 & -18 & -14 & -12 & -8 & -6 & -4 & $0^{*}$ \\
\hline \multirow[t]{4}{*}{9} & Feces & & 1 & & & & & & & & & & & & & 1 & & & $\|$ \\
\hline & NOC swabs & & & & & & & & & & & & & & & & & & $\|$ \\
\hline & Viremia & & & & & & & & & & & & & & & $\|$ & & & + \\
\hline & Effusions & & & & & & & & & & & & & & & $\|$ & $\|$ & & $\|$ \\
\hline \multirow[t]{4}{*}{11} & Feces & & & & & & - & & - & & & & & - & & & $\|$ & & $\|$ \\
\hline & NOC swabs & & & & & & & & & & & & & - & & & - & & $\|$ \\
\hline & Viremia & & & & & & & & - & & & & & - & - & & - & & - \\
\hline & Effusions & & & & & & + & & & & & & & & & & & & $\|$ \\
\hline \multirow[t]{4}{*}{12} & Feces & - & + & - & & - & - & - & - & - & - & - & - & - & + & & & $\|$ & $\|$ \\
\hline & NOC swabs & & & & & - & - & - & - & - & - & - & - & - & - & & & $\|$ & $\|$ \\
\hline & Viremia & - & & - & & - & - & - & - & - & - & - & $\|$ & + & + & & & - & \\
\hline & Effusions & $\|$ & & & & & & & & & & & & & & & & & $\|$ \\
\hline
\end{tabular}

+: FCoV positive; -: FCoV negative.

I, II: Type I or type II FCoV.

*: Samples were collected directly prior to euthanasia, except for cat 12 , from which the samples were taken after death. 
were detected in many excretions and secretions of cats dying of FIP (Table 3), thus providing a vehicle for catto-cat spreading.

Although directly following the first FCoV screening of all the animals in this shelter, cats shedding FCoV were caged separately, and transmission subsequently ceased, the mortality rate for this outbreak was high $(28 \%, 13 / 46)$. Three studies regarding outbreak of FIP have been reported previously. In a four-year study conducted in a closed breeding cattery, the average mortality was $17.3 \%$ [24], and in a 10-year study of a closed breeding colony, the mortality was $29.4 \%(5 / 17)$ [25]. Another epidemic study conducted in seven catteries/shelters revealed a $>10 \%$ mortality rate [20]. The high incidence of FIP in those closed breeding colonies might be influenced by the genetically predisposed breeding stock. In our study, only several FIP cats in this shelter were siblings, and the others were genetically unrelated. Our study demonstrates that without the influence of genetic predisposing factors, the mortality of FIP can still be high in a closed multi-cat environment as long as the spread of the disease-associated FCoV remains undetected.

In this multi-cat environment, three of the FIP cats were infected with not only type II FCoV but also coinfected with type I FCoV (Table 3). Type I FCoV were found only in the fecal samples, whereas type II FCoV were found in the diseased-associated samples, including body effusion, granulomatous tissue homogenates and cerebrospinal fluid. This finding indicates that in these dually infected animals, type II FCoV was the main cause of FIP. This finding is consistent with our previous finding that infection with type II FCoV appears to be significantly correlated with FIP [4].

The presence of $\mathrm{FCoV}$ in the whole blood at the terminal stage has been observed previously [26,27]; however, to our knowledge, fecal shedding of FIPV before the end stage of the disease has not been reported prior to this study. Shedding of this type II virus through fecal and nasal/oral/conjunctival routes can be detected in effusive form FIP up to six days before death. Another experimental infection study showed that inoculated viruses could only be recovered for approximately two weeks after inoculation, before clinical signs of disease develop [14]. Taken together, the transmission of FIPV might occur at the onset, before disease manifestation and at the terminal stage. In this outbreak, all the cats were housed together in an open room at the very beginning. After seven cats succumbed sequentially, all FCoV-positive cats were caged individually, and kept separated. The isolation eventually terminated the transmission of the disease. This outbreak, which killed 13 cats, allowed us to determine clearly that FIPV could be transmitted horizontally and showed that isolation of diseased cats should be taken into consideration in a multi-cat environment.

\section{Additional file}

Additional file 1: Recombination site analysis of FIPV from cats 1, 7, $9,10,11,12$ and 13 on the $S$ gene. Similarity plot analysis with the Kimura (two-parameter) distance model, neighbor-joining tree model and 100 bootstrap replicates showed a recombination event, and the putative crossover site is indicated with an arrow.

\section{Competing interests}

The authors declare that they have no competing interests.

\section{Authors' contributions}

YTW performed the sampling and preparation, FCoV detection, typing, $3 \mathrm{C}$ gene amplification and further analysis and prepared the manuscript. BLS supervised the sampling and treatment of all FIP animals and contributed to the preparation of the manuscript. LEH participated in $3 \mathrm{c}$ gene amplification, genetic analysis and the preparation of the manuscript. LLC conceived the study, participated in study design and coordination and contributed to the preparation of the manuscript. All authors read and approved the final manuscript.

\section{Acknowledgements}

The authors would like to thank the caregivers in this cat shelter, without whose help this study could not have been completed.

\section{Author details}

${ }^{1}$ Graduate Institute of Veterinary Medicine, School of Veterinary Medicine, National Taiwan University, Taipei 10617, Taiwan. ${ }^{2}$ Graduate Institute of Veterinary Clinical Sciences, School of Veterinary Medicine, National Taiwan University, Taipei 10617, Taiwan.

Received: 20 February 2013 Accepted: 25 June 2013 Published: 17 July 2013

\section{References}

1. Lai MMC, Perlman S, Anderson LJ: Coronaviridae. In Fields virology. Edited by Knipe DM, Howley PM, Griffin DE, Lamb RA, Martin MA, Roizman B, Straus SE. Philadelphia: Lippincott Willliams \& Wikins; 2007:1305-1335.

2. Pedersen NC: A review of feline infectious peritonitis virus infection: 1963-2008. J Feline Med Surg 2009, 11:225-258.

3. Pedersen NC, Black JW, Boyle JF, Evermann JF, McKeirnan AJ, Ott RL: Pathogenic differences between various feline coronavirus isolates. Adv Exp Med Biol 1984, 173:365-380.

4. Lin CN, Su BL, Wang CH, Hsieh MW, Chueh TJ, Chueh LL: Genetic diversity and correlation with feline infectious peritonitis of feline coronavirus type I and II: a 5-year study in Taiwan. Vet Microbio/ 2009, 136:233-239.

5. Addie DD, Schaap IA, Nicolson L, Jarrett O: Persistence and transmission of natural type I feline coronavirus infection. J Gen Virol 2003, 84:2735-2744.

6. Benetka V, Kubber-Heiss A, Kolodziejek J, Nowotny N, Hofmann-Parisot M, Mostl K: Prevalence of feline coronavirus types I and II in cats with histopathologically verified feline infectious peritonitis. Vet Microbio/ 2004, 99:31-42.

7. Hohdatsu T, Okada S, Ishizuka Y, Yamada H, Koyama H: The prevalence of types I and II feline coronavirus infections in cats. J Vet Med Sci 1992, 54:557-562.

8. Kummrow M, Meli ML, Haessig M, Goenczi E, Poland A, Pedersen NC, Hofmann-Lehmann R, Lutz H: Feline coronavirus serotypes 1 and 2: seroprevalence and association with disease in Switzerland. Clin Diagn Lab Immunol 2005, 12:1209-1215.

9. Lin CN, Chang RY, Su BL, Chueh LL: Full genome analysis of a novel type II feline coronavirus NTU156. Virus Genes 2013, 46:316-322.

10. Herrewegh AA, Smeenk I, Horzinek MC, Rottier PJ, de Groot RJ: Feline coronavirus type II strains 79-1683 and 79-1146 originate from a double recombination between feline coronavirus type I and canine coronavirus. J Virol 1998, 72:4508-4514. 
11. Vennema H, Poland A, Foley J, Pedersen NC: Feline infectious peritonitis viruses arise by mutation from endemic feline enteric coronaviruses. Virology 1998, 243:150-157.

12. Rottier PJ, Nakamura K, Schellen P, Volders H, Haijema BJ: Acquisition of macrophage tropism during the pathogenesis of feline infectious peritonitis is determined by mutations in the feline coronavirus spike protein. J Virol 2005, 79:14122-14130.

13. Chang HW, de Groot RJ, Egberink HF, Rottier PJ: Feline infectious peritonitis: insights into feline coronavirus pathobiogenesis and epidemiology based on genetic analysis of the viral 3c gene. J Gen Virol 2010, 91:415-420.

14. Stoddart ME, Gaskell RM, Harbour DA, Gaskell CJ: Virus shedding and immune responses in cats inoculated with cell culture-adapted feline infectious peritonitis virus. Vet Microbiol 1988, 16:145-158.

15. Herrewegh AA, de Groot RJ, Cepica A, Egberink HF, Horzinek MC, Rottier PJ: Detection of feline coronavirus RNA in feces, tissues, and body fluids of naturally infected cats by reverse transcriptase PCR. J Clin Microbiol 1995, 33:684-689.

16. Chomczynski P, Sacchi N: Single-step method of RNA isolation by acid guanidinium thiocyanate-phenol-chloroform extraction. Anal Biochem 1987, 162:156-159

17. Poland AM, Vennema $H$, Foley JE, Pedersen NC: Two related strains of feline infectious peritonitis virus isolated from immunocompromised cats infected with a feline enteric coronavirus. J Clin Microbiol 1996, 34:3180-3184

18. Pedersen $N C$, Liu H, Scarlett J, Leutenegger CM, Golovko L, Kennedy H, Kamal FM: Feline infectious peritonitis: role of the feline coronavirus $3 c$ gene in intestinal tropism and pathogenicity based upon isolates from resident and adopted shelter cats. Virus Res 2012, 165:17-28.

19. Foley JE, Poland A, Carlson J, Pedersen NC: Patterns of feline coronavirus infection and fecal shedding from cats in multiple-cat environments. J Am Vet Med Assoc 1997, 210:1307-1312.

20. Foley JE, Poland A, Carlson J, Pedersen NC: Risk factors for feline infectious peritonitis among cats in multiple-cat environments with endemic feline enteric coronavirus. J Am Vet Med Assoc 1997, 210:1313-1318.

21. Stavisky J, Pinchbeck G, Gaskell RM, Dawson S, German AJ, Radford AD: Cross sectional and longitudinal surveys of canine enteric coronavirus infection in kennelled dogs: a molecular marker for biosecurity. Infect Genet Evol 2012, 12:1419-1426.

22. Decaro N, Mari V, Elia G, Addie DD, Camero M, Lucente MS, Martella V Buonavoglia C: Recombinant canine coronaviruses in dogs, Europe. Emerg Infect Dis 2010, 16:41-47.

23. Decaro N, Buonavoglia C: An update on canine coronaviruses: viral evolution and pathobiology. Vet Microbiol 2008, 132:221-234.

24. Potkay S, Bacher JD, Pitts TW: Feline infectious peritonitis in a closed breeding colony. Lab Anim Sci 1974, 24:279-289.

25. Watt NJ, Maclntyre NJ, McOrist S: An extended outbreak of infectious peritonitis in a closed colony of European wildcats (Felis silvestris). J Comp Pathol 1993, 108:73-79.

26. de Groot-Mijnes JD, van Dun JM, van der Most RG, de Groot RJ: Natural history of a recurrent feline coronavirus infection and the role of cellular immunity in survival and disease. J Virol 2005, 79:1036-1044

27. Tsai HY, Chueh LL, Lin CN, Su BL: Clinicopathological findings and disease staging of feline infectious peritonitis: 51 cases from 2003 to 2009 in Taiwan. J Feline Med Surg 2011, 13:74-80.

\section{Submit your next manuscript to BioMed Central and take full advantage of:}

- Convenient online submission

- Thorough peer review

- No space constraints or color figure charges

- Immediate publication on acceptance

- Inclusion in PubMed, CAS, Scopus and Google Scholar

- Research which is freely available for redistribution

Submit your manuscript at www.biomedcentral.com/submit
Ciomed Central 